\title{
A secreted catalase contributes to Puccinia striiformis resistance to host-derived oxidative stress
}

\author{
Pu Yuan ${ }^{1 \dagger}$, Wenhao Qian ${ }^{1 \dagger}$, Lihua Jiang ${ }^{1}$, Conghui Jia ${ }^{1}$, Xiaoxuan Ma ${ }^{1}$, Zhensheng Kang ${ }^{1 *}$ and Jie Liu ${ }^{2^{*}}$ (D)
}

\begin{abstract}
Plants can produce reactive oxygen species (ROS) to counteract pathogen invasion, and pathogens have also evolved corresponding ROS scavenging strategies to promote infection and pathogenicity. Catalases (CATs) have been found to play pivotal roles in detoxifying $\mathrm{H}_{2} \mathrm{O}_{2}$ formed by superoxide anion catalyzed by superoxide dismutases (SODs). However, few studies have addressed $\mathrm{H}_{2} \mathrm{O}_{2}$ removing during rust fungi infection of wheat. In this study, we cloned a CAT gene PSCAT1 from Puccinia striiformis f. sp. tritici (Pst), which encodes a monofunctional heme-containing catalase. PsCAT1 exhibited a high degree of tolerance to $\mathrm{pH}$ and temperature, and forms high homopolymers.

Heterologous complementation assays in Saccharomyces cerevisiae reveal that the signal peptide of PsCAT1 is functional. Overexpression of PSCAT1 enhanced S. cerevisiae resistance to $\mathrm{H}_{2} \mathrm{O}_{2}$. Transient expression of PSCAT1 in Nicotiana benthamiana suppressed Bax-induced cell death. Knockdown of PSCAT1 using a host-induced gene silencing (HIGS) system led to the reduced virulence of Pst, which was correlated to $\mathrm{H}_{2} \mathrm{O}_{2}$ accumulation in HIGS plants. These results indicate that PsCAT1 acts as an important pathogenicity factor that facilitates Pst infection by scavenging host-derived $\mathrm{H}_{2} \mathrm{O}_{2}$.
\end{abstract}

Keywords: Wheat stripe rust, Puccinia striiformis f. sp. tritici, Catalase, Reactive oxygen species, Host-induced gene silencing

\section{Introduction}

The burst of reactive oxygen species (ROS) is the early immune responses of the host to pathogens. ROS (e.g. $\mathrm{O}_{2}{ }^{\cdot-}, \mathrm{H}_{2} \mathrm{O}_{2},{ }^{\circ} \mathrm{OH},{ }^{1} \mathrm{O}_{2}$ ) are considered to the unavoidable toxic byproducts of aerobic metabolism and can directly damage pathogens, thus, it is necessary for pathogens to effectively scavenge host-derived ROS to establish parasitic relationships (Mittler, 2017; Guo et al., 2019; Zheng et al., 2020). ROS are removed or detoxified by an array of antioxidative enzymes such as superoxide dismutase

\footnotetext{
*Correspondence: kangzs@nwsuaf.edu.cn; liujie2003@hotmail.com

${ }^{\dagger}$ Pu Yuan and Wenhao Qian contributed equally to this work.

${ }^{1}$ State Key Laboratory of Crop Stress Biology for Arid Areas and College of Plant Protection, Northwest A\&F University, Yangling, People's Republic of China

${ }^{2}$ State Key Laboratory of Crop Stress Biology for Arid Areas and College of Life Sciences, Northwest A\&F University, Yangling, People's Republic of China
}

(SOD), ascorbate peroxidase (APX), catalase (CAT), glutathione peroxidase (GPX), and peroxiredoxin (PRX) and antioxidants such as ascorbate (vitamin C), glutathione (GSH) and tocopherol (vitamin E) (Mittler et al., 2004; Foyer and Noctor, 2005).

Catalase (EC 1.11.1.6) is a type of terminal oxidase that widely exists in animals, plants and microorganisms. According to its physical and biochemical characteristics, CATs are divided into four types: typical catalase (monofunctional), catalase-peroxidase (bifunctional), non-heme catalase (pseudo-catalases) and minor catalase (Chelikani et al., 2004; Sooch et al., 2014). Monofunctional heme catalase is commonly a tetramer formed by four identical dumbbell-shaped subunits, with a heme prosthetic group at the catalytic center (Zámocký and Koller, 1999; Lee et al., 2007). Bifunctional catalase is a

(c) The Author(s). 2021 Open Access This article is licensed under a Creative Commons Attribution 4.0 International License, which permits use, sharing, adaptation, distribution and reproduction in any medium or format, as long as you give appropriate credit to the original author(s) and the source, provide a link to the Creative Commons licence, and indicate if changes were made. The images or other third party material in this article are included in the article's Creative Commons licence, unless indicated otherwise in a credit line to the material. If material is not included in the article's Creative Commons licence and your intended use is not permitted by statutory regulation or exceeds the permitted use, you will need to obtain permission directly from the copyright holder. To view a copy of this licence, visit http://creativecommons.org/licenses/by/4.0/. 
heme enzyme and has the catalytic activity of peroxidase (Zámocký and Koller, 1999; Kapetanaki et al., 2007). Pseudo-catalase is a heme-free catalase, which replaces the active center with a divalent manganese ion (Sooch et al., 2014). Minor catalase containing heme exhibits a very low level of catalytic activity, such as chloroperoxidase, bromoperoxidase, and catalase-phenol oxidase (Nicholls et al., 2001; Vetrano et al., 2005).

Previous studies have found that CATs are associated with cell development and differentiation, the production of metabolites (Yuan et al., 2021), and the response to oxidative stress, as an indispensable scavenger (Montibus et al., 2015). For example, in Saccharomyces cerevisiae, cta1 can confer the elimination of $\mathrm{H}_{2} \mathrm{O}_{2}$ produced by $\beta$-oxidation, and $c t t 1$ is involved in the responses to oxidative and osmotic stress (Jamieson, 1998). The catA and cat $B$ from Aspergillus nidulans both responded to different stress conditions (such as $\mathrm{H}_{2} \mathrm{O}_{2}$, heat-shock and paraquat) at the stage of spores or growing hyphae, respectively (Navarro et al., 1996; Kawasaki et al., 1997). The two monofunctional CATs of Neurospora crassa, NcCat1 (mainly expressed in conidia) and NcCat 3 (expressed in growing hyphae) can reduce toxic effects of oxidative stress (Michán et al., 2002; Yamashita et al., 2007). The mutant $\Delta$ catP of Beauveria bassiana is the most sensitive to $\mathrm{H}_{2} \mathrm{O}_{2}$ compared to the other CAT mutants, indicating that catP is essential for countering defense against oxidative stress (Wang et al., 2013).

In addition, CATs play an important role during infection of fungi by effectively detoxifying hydrogen peroxide released by host. For example, Aspergillus fumigatus contains two mycelia-specific catalase (CAT1, CAT2) and one spore-specific catalase (CATA), and mycelia of the double $\Delta$ cat $1 \Delta$ cat 2 mutant showed reduced virulence (Calera et al., 1997; Paris et al., 2003). CAT1-deficient homozygous null mutant strain of Candida albicans was far less virulent to mice (Wysong et al., 1998). An extracellular catalase CATB in Blumeria graminis f. sp. hordei (Bgh) can scavenge host-derived $\mathrm{H}_{2} \mathrm{O}_{2}$ during infection of barley, and may contribute to pathogenicity in Bgh (Zhang et al., 2004). In Magnaporthe grisea, the catalase gene $C A T B$ was 600 -fold up-regulated in response to exogenous $\mathrm{H}_{2} \mathrm{O}_{2}$ in vivo, and the catB mutant led to compromised pathogen fitness (Skamnioti et al., 2007). The virulence to Spodoptera litura larvae reduced by $33-47 \%$ in knockout mutants $\Delta$ cat $A, \Delta$ cat $P$ and $\Delta$ catD of $B$. bassiana, respectively (Wang et al., 2013). The cat1 overexpression strain in Metarhizium anisopliae reduced the germination time and increased the pathogenicity to Plutella xylostella larvae (Morales Hernandez et al., 2010). The catalase mutant $\Delta K a t G 2$ from Fusarium graminearum, exclusively located on the cell wall of invading hyphal cells, reduced the virulence in wheat spike infection (Guo et al., 2019). In addition, knocking out the transcription factors regulating the catalases, such as $\triangle s t u A$ mutant in A. snidulans (Scherer et al., 2002) and $\Delta c p t f 1$ mutant in Claviceps purpurea (Nathues et al., 2004), has a significant impact on virulence.

Wheat stripe rust caused by Puccinia striiformis f. sp. tritici (Pst) is one of the most destructive wheat diseases, resulting in serious wheat yield losses. Pst, an obligate biotrophic pathogen, hijacks the nutrients from host cells through haustoria, accompanied by ROS accumulation and host immunity induction (Chang et al., 2017; Wang et al., 2007). Removing host-derived ROS is crucial for Pst colonization in host-pathogen interactions. Previous studies have reported that two Pst SODencoding genes, PSSOD1 (a potential Zn-only SOD) and PSSOD2 (a Cu-only SOD), were deployed for counter defense against host-derived oxidative stress (Liu et al., 2016; Zheng et al., 2020). SODs catalyze the conversion of superoxide anions into molecular oxygen and hydrogen peroxide, and then CATs convert hydrogen peroxide into water and molecular oxygen, constituting the vital line of cellular defenses against ROS damages (Guo et al., 2019). However, few studies are available regarding the role of CAT during Pst infection of wheat. In this study, an extracellular CAT gene from Pst, PsCAT1, exhibiting a high expression level during the early stage of Pst infection, was characterized. Secretion and biochemical characteristics of PsCAT1 were determined by heterologous expression. In addition, the function of PsCAT1 was identified through overexpression and a host-induced gene silencing (HIGS) system. Our results indicate that PsCAT1 served as a virulence factor to promote Pst infection of wheat by counteracting hostderived oxidative stress.

\section{Results}

\section{Cloning and expression analysis of PsCAT1}

Extracellular antioxidant enzymes play pivotal roles during infection of pathogens (Liu et al., 2016). In the Pst genome, four genes annotated as CATs were designated PsCAT1, PsCAT2, PsCAT3, PsCAT4. PsCAT1, PsCAT2 and PsCAT3 were found to contain the signal peptides using signalP 4.1 (Fig. S1). In addition, semi-quantitative reverse transcription PCR (sqRT-PCR) analysis showed that PsCAT1 was continuously expressed at a high level in urediniospores and infection structures (Fig. S2). PSCAT2 showed a lower transcript level during infection compared with ungerminated urediniospores (Fig. S2), while PsCAT3 was not expressed in all developmental early stages (Fig. S2). Thus, PsCAT1 was subjected to more detailed functional characterization as described in the following sections.

PSCAT1 was amplified by RT-PCR using a CYR31infected Suwon 11 (Su11) cDNA sample as a template. 
The open reading frame (ORF) of PSCAT1 consists of 1557 nucleotides and is predicted to encode a polypeptide of 518 amino acids with a calculated molecular weight of $62,280 \mathrm{Da}$, an isoelectric point (pI) of 8.63. In addition, two domains (catalase and catalase-related immune-responsive domains), and active sites of Asparagine and Histidine for metal iron binding were identified in the PsCAT1 protein sequence by HMMER analysis (Fig. S3).

The 518 amino acid sequence was used as a query sequence to search the most up-to-date databases (NCBI). Homologous proteins from other fungi with the highest similarities to PsCAT1 were determined. The protein sequence showed $63.23 \%$ identity with the CAT protein from Puccinia graminis f. sp. tritici CRL 75-36-700-3 (GenBank accession number XP_003329286.2), and 42.45\% identity with the CAT protein from Puccinia sorghi (GenBank accession number KNZ48073.1). The phylogenetic analysis of PsCAT1 with homologous proteins from other fungi revealed that PsCAT1 displays greater similarity to CATs from basidiomycetous fungi, especially rust fungi, compared with those from ascomycetous fungi (Fig. S4). These results indicate PsCAT1 possibly encodes a typical catalase.

\section{Biochemical characterization of PsCAT1}

The recombinant plasmid pET15b-SUMO-PsCAT1 was transformed to E. coli BL21(DE3) plysS to induce the expression of the recombinant PSCAT1 protein using 0.4 mM IPTG, as shown in the SDS-PAGE profiles (Fig. 1a). Enzymatic characterization of PsCAT1 were performed with the purified PsCAT1 protein obtained by immobilized-nickel affinity chromatography. SDS-PAGE and Western blotting analysis (anti-His antibody) showed that the expressed fusion protein was about 73 $\mathrm{kDa}$ containing the His 6 in series with the SUMO tag $(\sim 12 \mathrm{kDa})$ (Fig. 1a and Fig. 1b), which is consistent with the predicted molecular weight of PsCAT1.

The Michaelis-Menten kinetics of PsCAT1 was then measured using the Lineweaver-Burk plot method (Chang et al., 2017). Km and Vmax were determined to be $27.06 \mathrm{mM}$ and $20.20 \mathrm{mM} \mathrm{mg}^{-1} \mathrm{~min}^{-1}$ under optimal conditions (Fig. 1c). The optimum temperature was approximately $40^{\circ} \mathrm{C}$, and a high enzyme activity was measured at $70^{\circ} \mathrm{C}$, indicating that PSCAT1 has a strong tolerance to high temperature (Fig. 1d). The $\mathrm{pH}$ optimum was determined to be approximately $\mathrm{pH}$ 8.0. Only slight change was observed in enzyme activity, from $\mathrm{pH} 5$ to 12, whereas the enzyme was almost inactivated at $\mathrm{pH} 13$ (Fig. 1e). In addition, metal cations also showed different effects on the enzyme activity of PsCAT1. Including $0.2 \mathrm{mM} \mathrm{Fe}^{2+}$ in the reaction can increase the enzyme activity by $68 \%$, whereas $\mathrm{Zn}^{2+}, \mathrm{Cu}^{2+}$ and $\mathrm{Mn}^{2+}$ have no obvious effect on the PsCAT1 enzyme activity (Fig. 1f).

\section{PsCAT1 potentially forms homopolymers}

To investigate the polymerization of PsCAT1, the purified PsCAT1 protein sample was subjected to size exclusion chromatography. The native molecular weight of PsCAT1 was determined to be $1690.27 \mathrm{kDa}$ (Fig. S5a; Fig. 2a), which was approximately 23 times as high as that of the PsCAT1 monomer. The sample in absorption peak was verified as the target protein by Western blotting (Fig. S5b). As shown in Fig. 2a, the elution peak of $8.48 \mathrm{ml}$ is beyond the upper limit of the calibration curve, the molecular weight of the polymer cannot be accurately measured. Then, the purified PsCAT1 protein denatured with urea was separated by gel filtration chromatography, again. The result showed that there were two absorption peaks, $8.35 \mathrm{ml}$ (a high polymer) and $14.69 \mathrm{ml}$ (a monomer), respectively (Fig. S5c). Western blotting analysis further indicated that the two absorption peaks are the different forms of the target protein (Fig. S5d). These results suggest that PsCAT1 is a high polymer.

To further identify the self-interaction of PsCAT1, the recombinant plasmids pGADT7-PSCAT1 and pGBKT7PSCAT1 were co-transformed into $S$. cerevisiae strain AH109. Co-transformations with pGBKT7-Lam and pGADT7-T, pGADT7 and pGBKT7-PSCAT1, and pGBKT7 and pGADT7-PSCAT1 were used as the negative controls, whereas the transformants containing pGBKT7-53 and pGADT7-T acted as a positive control. The interactions were assessed by the survival of yeast on the selection medium SD/-Leu-Trp-His-Ade (SDLWHA) and the production of $\beta$-galactosidase. As shown in Fig. 2b, reporter activation suggested that PsCAT1 is capable of interacting with itself.

In addition, bimolecular fluorescence complementation (BiFC) assay in transiently transformed $N$. benthamiana leaves was performed to confirm the polymerization of PsCAT1. Similar to the positive control (Fig. 2c), strong fluorescence signals were observed when agrobacteria carrying $\mathrm{PSPYNE}(\mathrm{R}) 173-P S C A T 1$ and pSPYCE(M)-PsCAT1 were co-infiltrated into $N$. benthamiana leaves (Fig. 2c). However, with the coexpression of pSPYNE(R)173-PsCAT1 and the empty pSPYCE(M) vector, or pSPYCE(M)-PsCAT1 and the empty pSPYNE(R)173 in $N$. benthamiana leaves, no fluorescence was visualized (Fig. 2c). These results indicate that PsCAT1 can form homopolymers.

\section{Functional validation of the signal peptide of PsCAT1}

To functionally validate the SignalP 4.1 predictions, the signal peptide of PsCAT1 was tested using the S. cerevisiae. Firstly, the recombinant plasmids pSUC2- 
$\mathbf{a}$

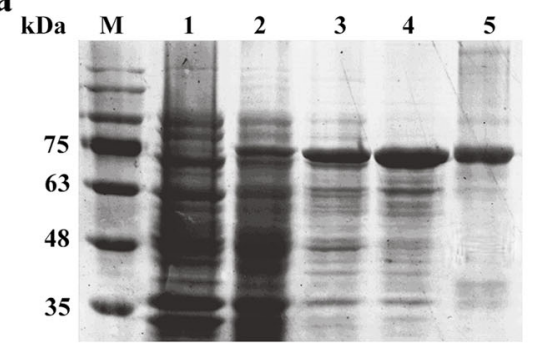

c

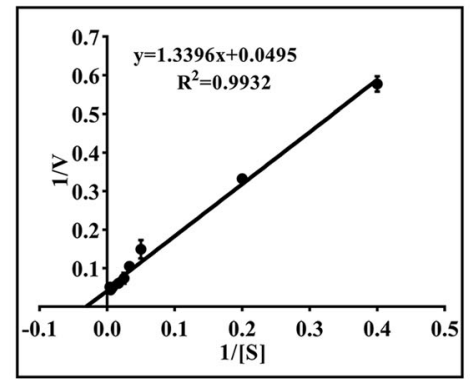

e

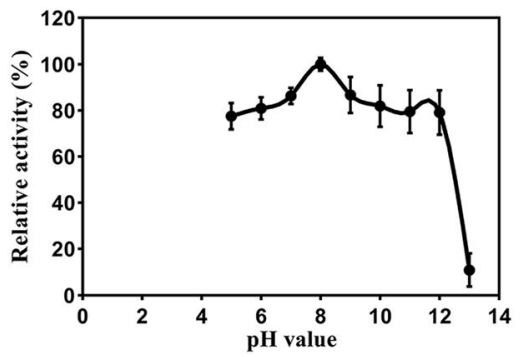

b

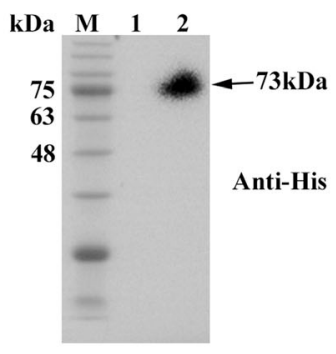

d

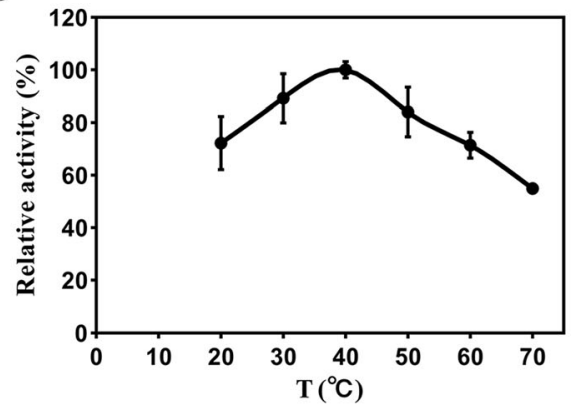

f

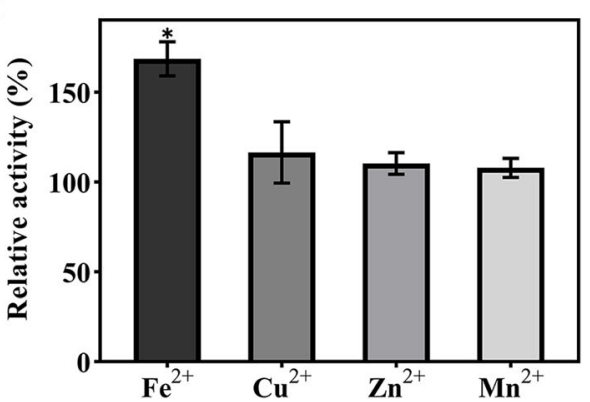

Fig. 1 Purification and biochemical characterization of PsCAT1. a. The SDS-PAGE profiles of PSCAT1 in E. coli BL21(DE3) plysS. Lane 1, uninduced E. coli cell lysates harboring pET15b-SUMO-PSCAT1; lane 2, E. coli cell lysates harboring pET15b-SUMO-PSCAT1 induced by IPTG; lane 3 and 4, soluble and insoluble fractions from the cell culture expressing PSCAT1; lane 5, the purified PsCAT1 fusion proteins; M, marker. b. Western blotting analysis of the purified PSCAT1 fusion proteins. Lane 1, uninduced E. coli cell lysates harboring pET15b-SUMO-PSCAT1; lane 2, the purified PsCAT1 fusion proteins; M, marker. $\mathbf{c}$ Lineweaver-Burk plot for PsCAT1. $\mathbf{d}$ and $\mathbf{e}$. Thermal and pH stability of the purified PsCAT1 proteins. f. Effects of metal ions on the activity of the purified PsCAT1 proteins. $\mathrm{Fe}^{2+}, \mathrm{Fe}_{2}\left(\mathrm{SO}_{4}\right)_{3} ; \mathrm{Cu}^{2+}, \mathrm{CuSO} 4 \cdot 5 \mathrm{H}_{2} \mathrm{O} ; \mathrm{Zn}^{2+}, \mathrm{ZnSO}_{4} \cdot 7 \mathrm{H}_{2} \mathrm{O} ; \mathrm{Mn}^{2+}, \mathrm{MnSO}_{4} \cdot \mathrm{H}_{2} \mathrm{O}$. Asterisks indicate a significant difference $(P<0.05)$ compared with the control using Student's t-test

PsCAT1 $1_{s p}$, pSUC2-Avr1b $b_{s p}$ pSUC2-Mg87 $1_{1-75}$ and the empty vector pSUC2 were transformed into the invertase mutated yeast strain YTK12, respectively. pSUC2$M g 87_{1-75}$ and the empty pSUC2 vector were used as the negative controls. pSUC2-Avr1 $b_{s p}$ served as a positive control. The results showed that both the pSUC2$P S C A T 1_{s p}$ and pSUC2-Avr1 $b_{s p}$ fused constructs enabled YTK12 to grow on CMD-W media (yeast can grow without invertase secretion) and YPRAA media (yeast can grow only when invertase is secreted) (Fig. 3a). Additionally, in the color reaction, the yeast strains transformed by pSUC2-PsCAT1 $1_{s p}$ and pSUC2-Avr1b restored the secretion function of invertase, thus the invertase enzymatic activity can be detected by the reduction of 2,3,5-Triphenyltetrazolium chloride (TTC) to insoluble red colored 1,3,5-Triphenylformazan (TPF)
(Fig. 3b). These results confirmed that the signal peptide of PsCAT1 was functional.

\section{PsCAT1 enhances $S$. cerevisiae resistance to ROS}

To identify the function of PsCAT1, the empty vector pDR195 and the recombinant plasmid pDR195-PsCAT1 were transformed into a S. cerevisiae strain YNL241C, respectively. The growth of the positive transformants was monitored on synthetic complete (SC) media containing different concentrations of $\mathrm{H}_{2} \mathrm{O}_{2}$. The result showed that PsCAT1 conferred enhanced resistance of S. cerevisiae to $\mathrm{H}_{2} \mathrm{O}_{2}$ compared with the control (Fig. 4a). Additionally, the growth curves of the above-mentioned two strains were constructed in liquid SC media with 1 $\mathrm{mM} \mathrm{H}_{2} \mathrm{O}_{2}$. As shown in Fig. 4b, the $S$. cerevisiae strain carrying pDR195-PSCAT1 grew significantly faster than 


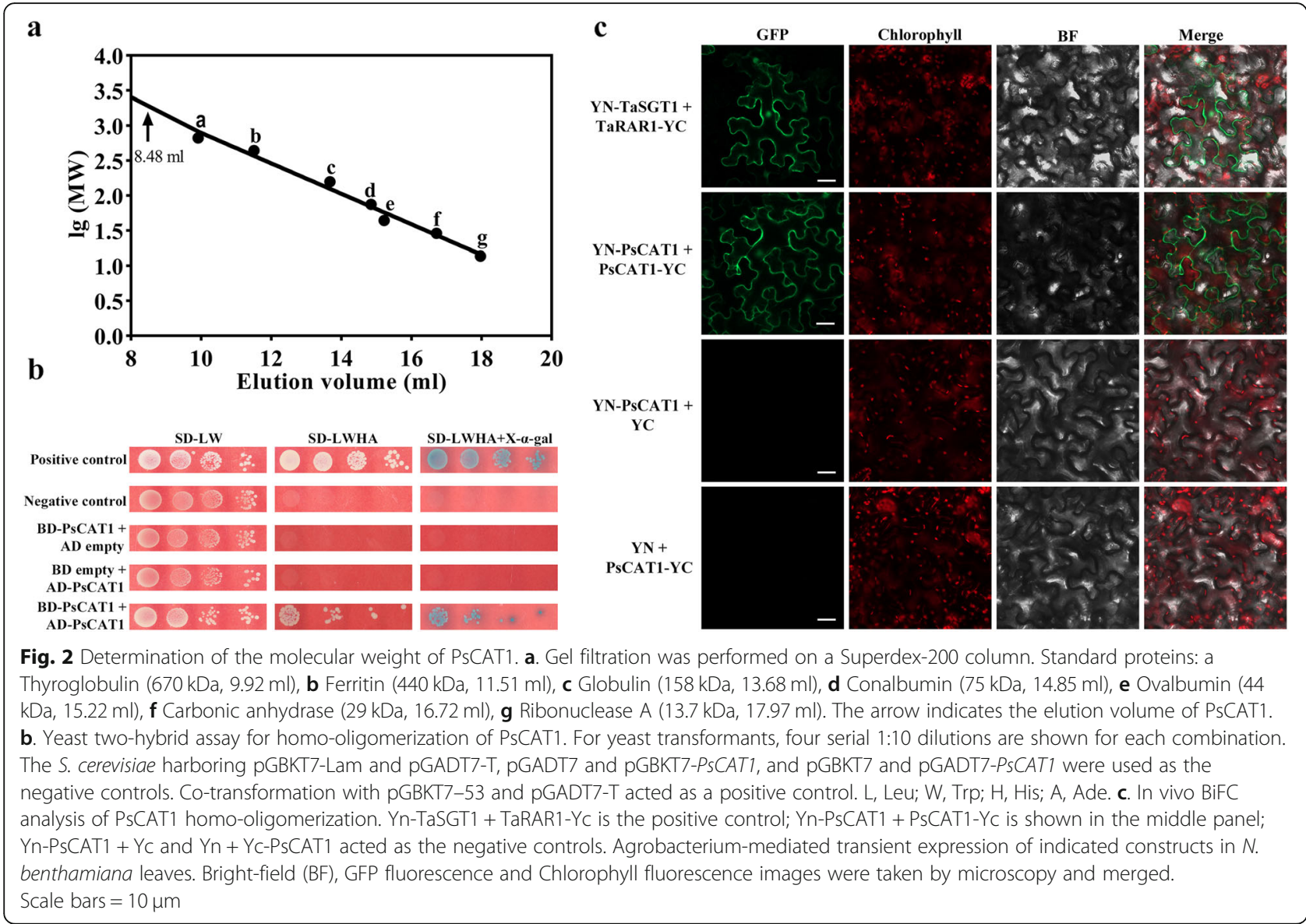

the control harboring the empty pDR195 vector. To further confirm that PsCAT1 was secreted extracellularly to remove exogenous $\mathrm{H}_{2} \mathrm{O}_{2}$, the culture supernatants of the $S$. cerevisiae with pDR195-PSCAT1 were determined using Western blotting. A $\sim 63 \mathrm{kDa}$-band was clearly exhibited (Fig. 4c), which is in accordance with the above result that PsCAT1 possess functional signal peptide.

\section{PsCAT1 suppresses Bax-induced cell death by scavenging ROS}

To clarify whether PsCAT1 functions in suppressing the host defence responses, PSCAT1 was transiently expressed in tobacco leaves. When $N$. benthamiana leaves were infiltrated with $A$. tumefaciens strains individually carrying PVX-PSCAT1 or PVX-GFP (the negative control, NC), no cell death was observed (Fig. 5b; circle 1,3); tobacco leaves infiltrated with Bax (a proapoptotic protein from mouse that triggers a hypersensitive response (HR)-like cell death response in plants) + NC (Fig. 5b; circle 4) or Bax only (Fig. 5b; circle 5) both showed a similar cell death phenotype (after 4days). However, when PsCAT1 was infiltrated prior to Bax for $24 \mathrm{~h}$, cell death was significantly suppressed (Fig. 5b; circle 2). Accordingly, $\mathrm{H}_{2} \mathrm{O}_{2}$ production in $N$. benthamiana leaves was detected by DAB staining. The result showed that the expression of PsCAT1 led to less $\mathrm{H}_{2} \mathrm{O}_{2}$ generated in the injection site circle 2 compared with circles 4 and 5 (Fig. 5c). In addition, trypan blue staining was used to assess cell death. As a result, the injection site circles 4 and 5 have a large number of necrotic cells, in contrast, only mild necrosis was observed in circle 2 (Fig. 5d). To confirm that PsCAT1, GFP and Bax were successfully expressed in $N$. benthamiana leaves, Western blotting analysis was performed. As shown in Fig. S6, anti-HA antibody, anti-GFP antibody and anti-Bax antibody can detect the expression of the HA-PsCAT1, GFP and Bax proteins, respectively. These results indicate that PsCAT1 can function as a ROS scavenger to counteract the host defence responses.

\section{Silencing of PsCAT1 by HIGS reduces the virulence of Pst infection of wheat}

To investigate the function of PsCAT1 during Pst infection of wheat, we used the HIGS technique to silence PsCAT1 in Pst. Wheat seeding inoculated with barley stripe mosaic virus (BSMV) showed mild chlorotic mosaic symptoms at 10 days after inoculation (dai), and a photo-bleaching phenotype also observed in the TaPDS 


\section{a}

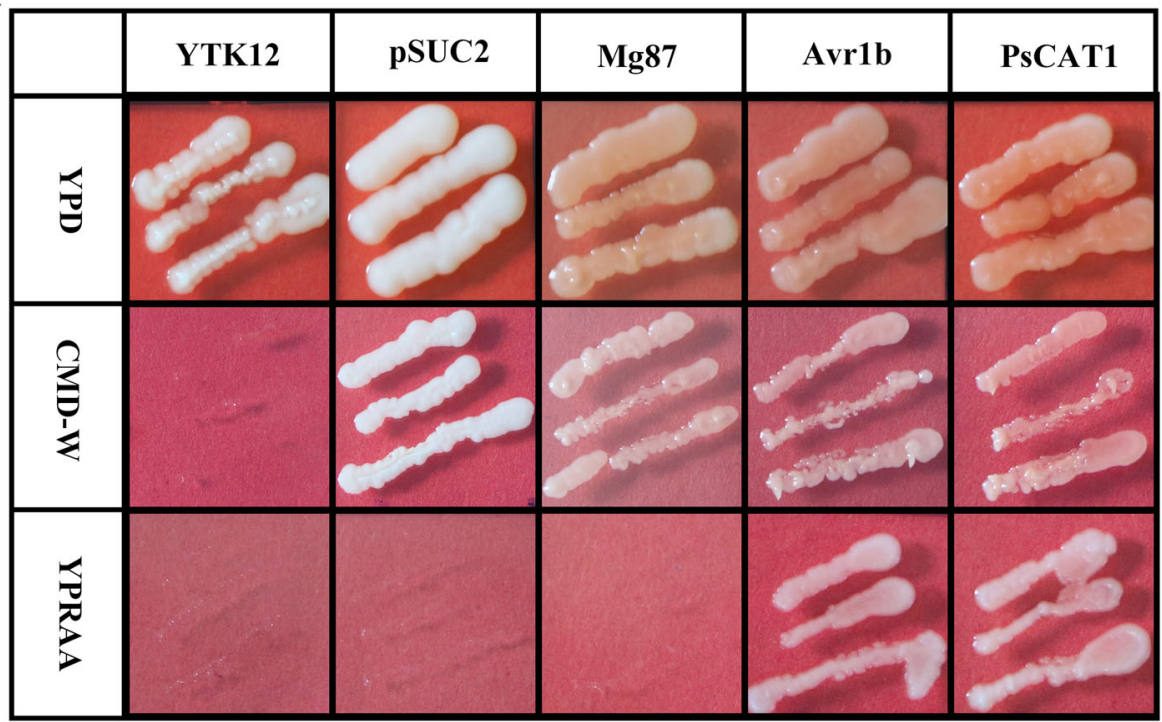

$\mathbf{b}$

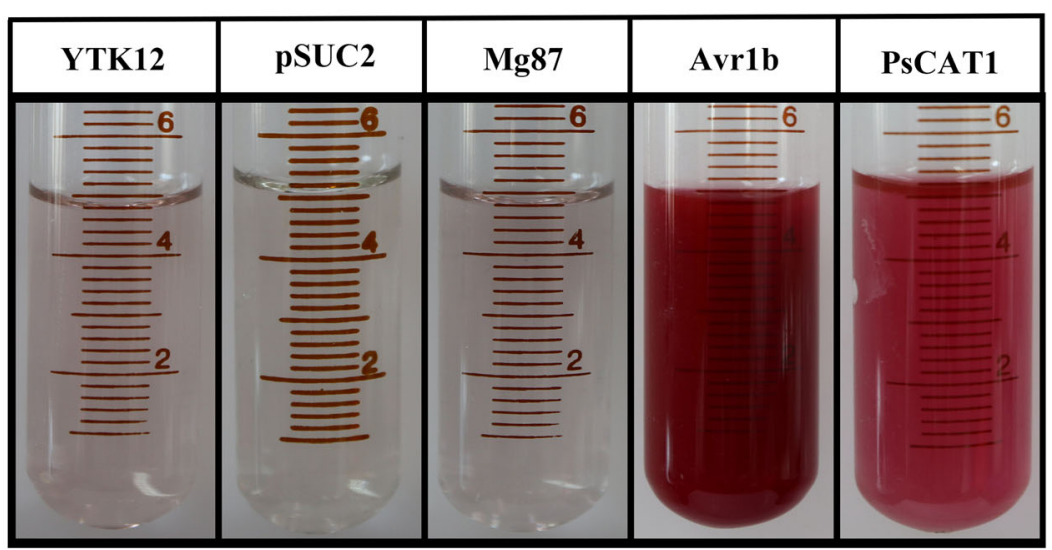

Fig. 3 Functional validation of the signal peptide of PsCAT1. a. The PsCAT1 or Avr1b signal peptides or the first 25 amino acids of Mg87 were fused in-frame to the invertase sequence in the PSUC2 vector and transformed into the yeast YTK12 strain. Controls include the untransformed YTK12 strain and YTK12 carrying the pSUC2 vector. Strains that are unable to secrete invertase can grow on CMD-W media but not on YPRAA media $\mathbf{b}$. The color reaction was used to verify the function of the PSCAT1 signal peptide. The extracellular invertase enzyme activity was detected by the reduction of 2,3,5-Triphenyltetrazolium Chloride (TTC) to insoluble red colored 1,3,5-Triphenylformazan (TPF)

(TaPDS: wheat phytoene desaturase gene)-silenced wheat leaves (Fig. 6a). After Pst inoculation, the wheat plants inoculated with BSMV-PSCAT1as1 (carrying a 142-bp fragment of PsCAT1) and BSMV-PsCAT1as2 (carrying a 133-bp fragment of PsCAT1) exhibited a significant reduction in sporulation compared with the control BSMV- $\gamma$-infected wheat leaves at 15 dai (Fig. 6b).

Subsequently, fungal biomass in the host tissue was measured as described by Huai et al. (2019), to examine whether the reduction in sporulation was related to hyphal growth restriction. In Pst-infected wheat leaves inoculated with BSMV-PSCAT1as1 and BSMVPSCAT1as2, the fungal biomass was obviously reduced by $48 \%$ and $38 \%$ respectively, compared with the controls inoculated with BSMV- $\gamma$ (empty BSMV) (Fig. 6c). This result demonstrated that fungal development was impeded, probably as a result of the the silencing of PSCAT1.

To clarify whether PSCAT1 was successfully silenced, the relative transcript level of PSCAT1 was measured using qRT-PCR in Pst-infected wheat leaves. The results showed that the PsCAT1 transcript in BSMV-PsCAT1as1-inoculated leaves was reduced by $68 \%, 57 \%, 28 \%$ and $63 \%$ at $24,48,72$ and 120 hpi respectively; in leaves inoculated with BSMV-PsCAT1as2, the PsCAT1 expression level was decreased by $68 \%, 77 \%, 81 \%$ and $63 \%$ respectively, compared with BSMV- $\gamma$-infected wheat leaves (Fig. 6d). These results indicate that the expression of PSCAT1 was efficiently knocked down by BSMV-HIGS. 

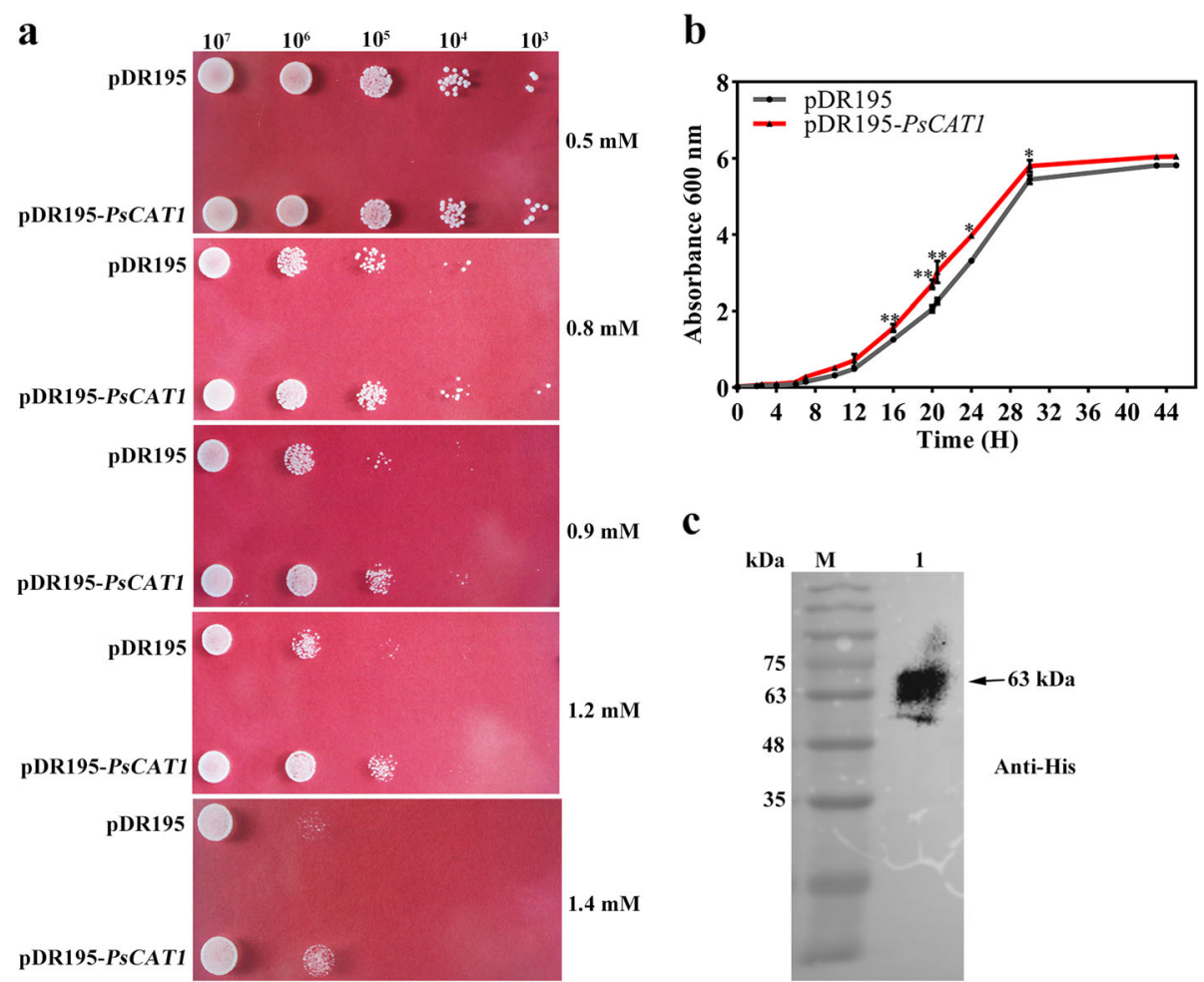

Fig. 4 Overexpression of PSCAT1 in S. cerevisiae. a. A spot assay of the S. cerevisiae strain YNL241C harboring pDR195 or pDR195-PSCAT1 on SD/

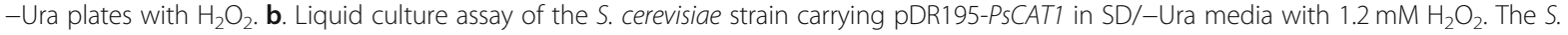
cerevisiae harboring pDR195 empty vector was used as the control. Overexpression of PSCAT1 significantly enhanced S. cerevisiae resistance to ROS stress compared with the control. c. Western blotting analysis of PSCAT1 expression in S. cerevisiae

\section{HIGS of PsCAT1 impaired fungal growth and enhanced $\mathrm{H}_{2} \mathrm{O}_{2}$ accumulation}

To determine PsCAT1 contribution to Pst pathogenicity, histological changes in the pathogen were observed in HIGS wheat plants infected with Pst, based on staining with wheat germ agglutinin (WGA). As shown in Fig. 7k and Fig. S6a, the number of hyphal branches (HB), haustorial mother cells (HMC) and haustoria $(\mathrm{H})$ in BSMVPsCAT1as1 or BSMV-PsCAT1as2 inoculated wheat plants infected with Pst were similar $(P>0.05)$ to those of the control at 24 and $48 \mathrm{hpi}$, respectively; whereas the hyphal length has decreased significantly (Fig. 7a, b, f, g and l). Moreover, there was no obvious difference in the formation of secondary hyphae compared with the control at 24 and 48 hpi (Fig. S6b), while the infection area was significantly reduced compared to control at $120 \mathrm{hpi}$ (Fig. 7c, $\mathrm{h}$ and $\mathrm{m}$ ). Furthermore, DAB staining was performed to determine the effect of silencing PsCAT1 on $\mathrm{H}_{2} \mathrm{O}_{2}$ accumulation in response to Pst infection in wheat. The results showed that $\mathrm{H}_{2} \mathrm{O}_{2}$ accumulation was significantly increased, especially in the anterior part of the HMC, in the wheat seedings inoculated with BSMVPsCAT1as1 and BSMV-PsCAT1as2 compared with the control plants at 24 and 48 hpi (Fig. $7 \mathrm{~d}, \mathrm{e}, \mathrm{i}, \mathrm{j}$ and $\mathrm{n}$ ). These results revealed that the PSCAT1-silenced Pst severely affects its elimination of host-derived $\mathrm{H}_{2} \mathrm{O}_{2}$, resulting in blocked fungal growth.

\section{Discussion}

Higher eukaryotes use ROS originated from the oxidative burst to eliminate invading pathogens. During the coevolution of pathogens and their hosts, pathogens have coopted the antioxidant enzymes and molecules for normal ROS removing to evade oxidative killing so that survival and persistence are ensured (Cuéllar-Cruz et al., 2008). Although CATs, as a kind of key antioxidant enzymes, play a pivotal role in fungal development and exogenous stress responses, little information is available regarding the role of CATs in plant-pathogen interactions. In this study, a Pst CAT-encoding gene (PsCAT1) was cloned for the first time. Heterologous expression of PsCAT1 could confer enhanced resistance to $\mathrm{H}_{2} \mathrm{O}_{2}$, while knockdown of PSCAT1 in the wheat-Pst interaction led to fungal growth restriction. These results indicate that PsCAT1 functions as a virulence factor to promote Pst infection.

Numerous studies have found that CATs exhibited high activity over a broad $\mathrm{pH}$ and temperature range. For example, the CAT from Rhodospirillum rubrum S1 had a high activity in $\mathrm{pH}$ range from 5.0 to 11.0 and 
a

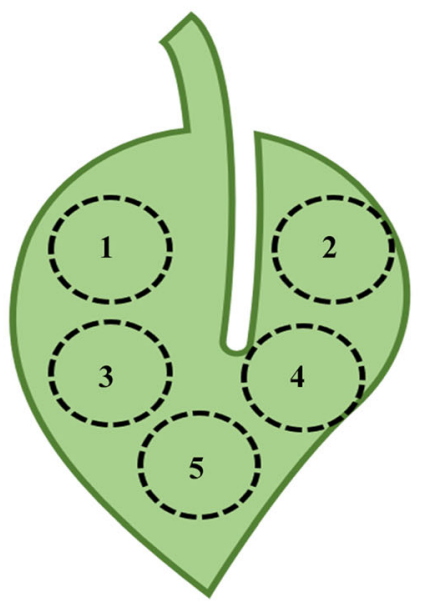

C

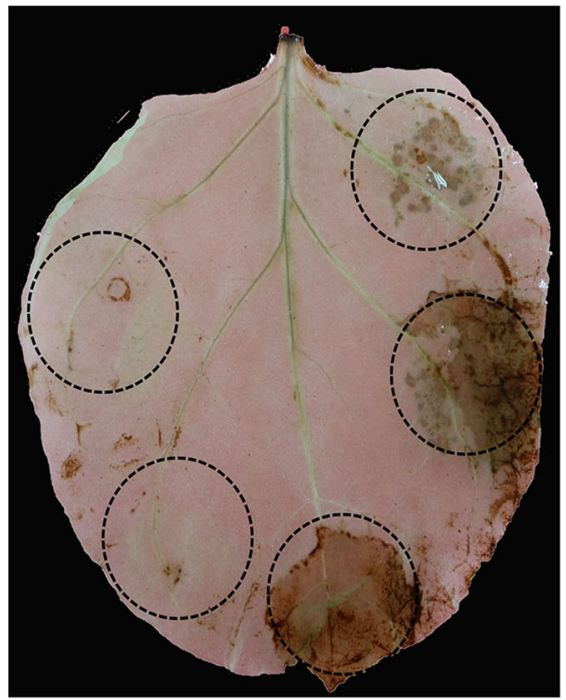

b

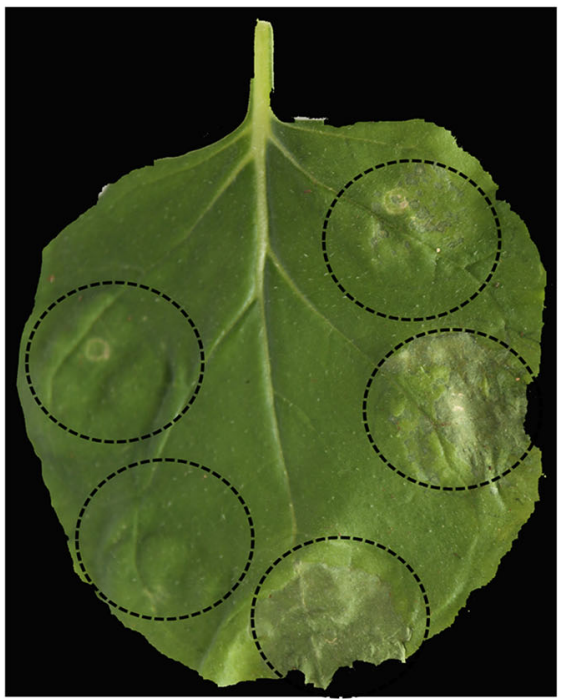

d

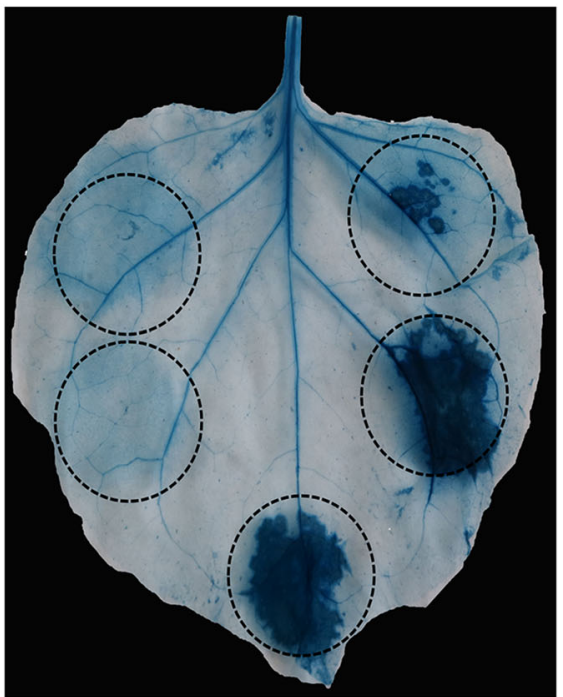

Fig. 5 Transient expression of PSCAT1 in N. benthamiana. a. Five injection sites on tobacco leaves. 1, PSCAT1; 2, PsCAT1 + Bax (infiltrated $24 \mathrm{~h}$ later); 3, empty vector; 4, empty vector + Bax (infiltrated $24 \mathrm{~h}$ later); 5 , Bax. b. Tobacco leaves were infiltrated with $A$. tumefaciens cells carrying PSCAT1, an empty vector or Bax alone (circles 1, 3,5), infiltrated with A. tumefaciens cells containing PsCAT1 or empty vector and followed $24 \mathrm{~h}$ later by a second infiltration of A. tumefaciens cells carrying Bax (circles 2, 4). Photos were taken from 4 days after the second infiltration. $\mathbf{c}$. $\mathrm{H}_{2} \mathrm{O}_{2}$ accumulation in N. benthamiana leaves was determined by DAB staining. d. Cell necrosis was determined by Trypan Blue staining

temperature range from 20 to $60^{\circ} \mathrm{C}$ (Lee et al., 2007). A CAT, KatP, from Pigmentiphaga sp. DL-8 remained active and stable in a wide $\mathrm{pH}$-stable range of $4.0-11.0$ and the enzyme activity can be detected at $5-70^{\circ} \mathrm{C}$ (Dong et al., 2015). High tolerance of CATs to temperature $\left(25\right.$ to $\left.50^{\circ} \mathrm{C}\right)$ and $\mathrm{pH}(4.0$ to 11.5$)$ was also found in Corynebacterium glutamicum (Yang et al., 2020). In the present study, PsCAT1 was found to display strong tolerance to temperature and $\mathrm{pH}$. Considering that PsCAT1 contains a functional signal peptide and is secreted into the host-pathogen interface to remove ROS, this kind of tolerance capability of PsCAT1 may ensure a high efficiency of eliminating the hostderived $\mathrm{H}_{2} \mathrm{O}_{2}$ even under intricate environmental conditions.

Monofunctional CATs normally exist as a dumbbellshaped tetramer of four identical subunits, with a molecular weight of $200-340 \mathrm{kDa}$, and with a haem prosthetic group at the catalytic center (Sooch et al., 2014). Here, the polymerization of PsCAT1 was determined using size exclusion chromatography. The selfinteraction of PsCAT1 in vivo was further confirmed by 
a

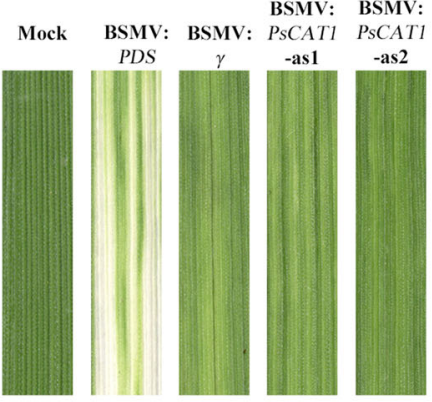

b

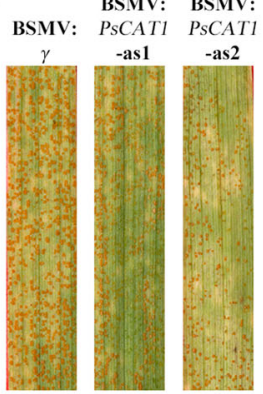

c

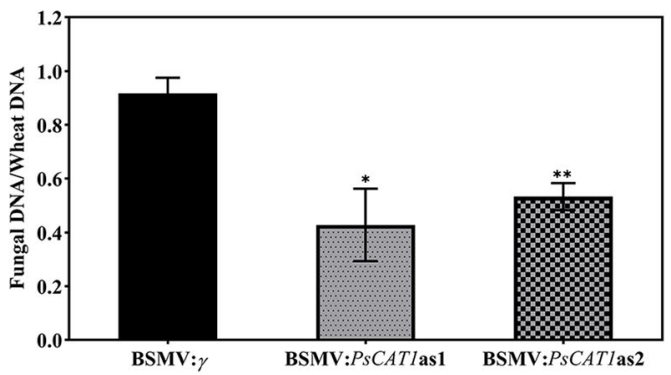

d

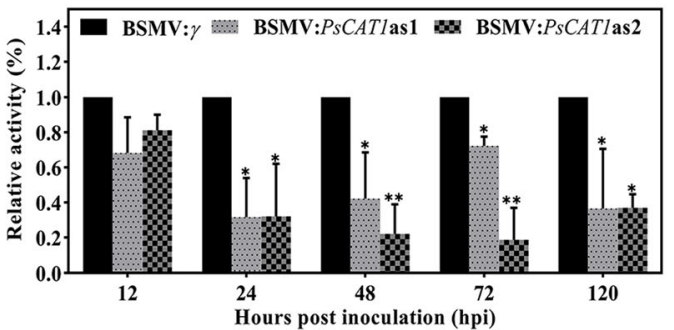

Fig. 6 Silencing of PSCAT1 in the wheat-Pst interaction using HIGS leads to reduced virulence. a. Mild chlorotic mosaic symptoms were observed on the fourth leaves of seedlings at $10 \mathrm{dpi}$ with BSMV, and bleaching was evident on the fourth leaves of plants infected by BSMV:TaPDS. Mock, wheat leaves inoculated with FES buffer. $\mathbf{b}$. Disease phenotypes of the fourth leaves pre-inoculated with BSMV and then challenged with CYR31. c. Fungal biomass measurements using real-time PCR analysis of total DNA extracted from the wheat leaves infected by CYR31 at 15 dpi. Ratio of total fungal DNA to total wheat DNA was assessed using the wheat gene TaEF-1a and the Pst gene PstEF1. d. Silencing efficiency assessment of PSCAT1 in Pst. Wheat leaves inoculated with BSMV:Y and sampled after inoculation with CYR31 were used as the controls. The data were normalized to the expression level of TaEF-1a. The mean \pm SD from four independent samples is presented. Asterisks indicate a significant difference $(P<0.05)$ using Student's t-test

yeast two-hybrid and BiFC assays. By contrast, the molecular weight is approximately 23 times as high as that of the PsCAT1 monomer, which is inconsistent with the previously reported CATs. These results suggest that PsCAT1 probably encodes a novel monofunctional heme catalase functioning as a high polymer. During wheatPst interactions, the formation of homopolymers appears to facilitate increasing enzymatic activity of PsCAT, resulting in faster ROS scavenging and establishment of parasitic relationships.

Extracellular CATs have been shown to endow elevated resistance to exogenous stress responses (Garre et al., 1998). For example, Cuéllar-Cruz et al. (2008) found that high resistance to oxidative stress in the fungal pathogen Candida glabrata is mediated by a single catalase, Cta1p. The gastric pathogen Helicobacter pylori catalases protect the bacterium against oxidative stress (Benoit and Maier, 2016). Heterologously expressed Debaryomyces hansenii DhCTA1 and DhCTT1 genes conferred enhanced tolerance of $S$. cerevisiae to oxidative stress (González et al., 2020). In the present study, PsCAT1 was overexpressed in S. cerevisiae treated with exogenous ROS. The results showed that PSCAT1 could enhance $S$. cerevisiae resistance to exogenous $\mathrm{H}_{2} \mathrm{O}_{2}$, indicating that PsCAT1 can be secreted from the $S$. cerevisiae cells and scavenge exogenous ROS. In addition, transient expression in tobacco significantly suppressed Bax-induced cell death. Therefore, it is a reasonable inference that highly-expressed and secreted PsCAT1 is in favor of Pst infection, since ROS elimination in the hostpathogen interface not only could protect $P s t$ from oxidative damage, but also may suppress HR-like cell death of host cells induced by ROS.

Catalases have been found to contribute to pathogen virulence by participating in ROS removing. For example, in Xanthomonas oryzae pv. oryzae (Xoo). Deletion of the CAT gene cat $B$ drastically impaired bacterial viability in the presence of extracellular $\mathrm{H}_{2} \mathrm{O}_{2}$ and reduced CAT activity, demonstrating that $\mathrm{CatB}$ contributes to $\mathrm{H}_{2} \mathrm{O}_{2}$ detoxification in Xoo. In addition, $\Delta$ catB displayed shorter bacterial blight lesions and reduced bacterial growth in rice compared to the wild-type stain, indicating that CatB plays essential roles in the virulence of $X o o$ (Yu et al., 2016). Aflatoxin production and virulence were significantly decreased in the cta1 deletion mutant of Aspergillus flavus compared with the WT and complementary strains (Zhu et al., 2020). While the extracellular CAT KatG2 in the rice blast fungus Magnaporthe 


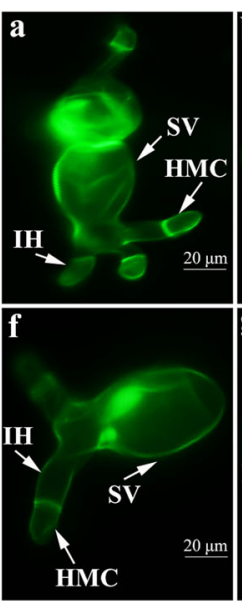

$\mathbf{k}$
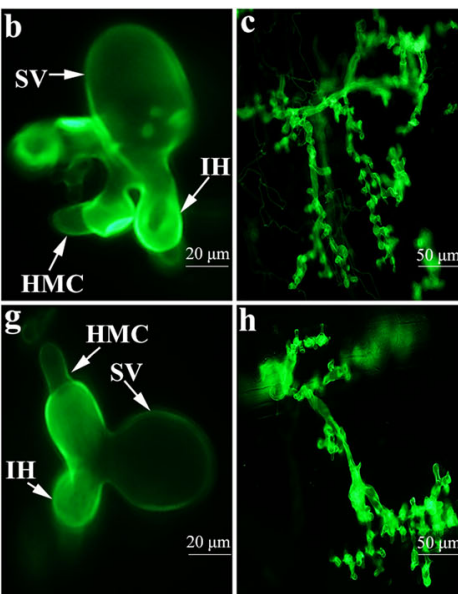
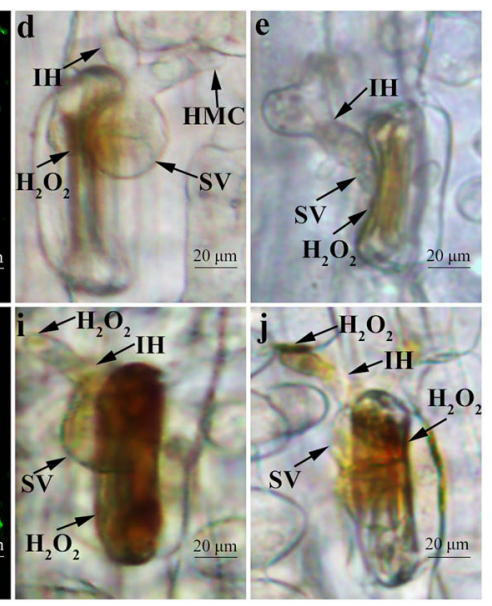
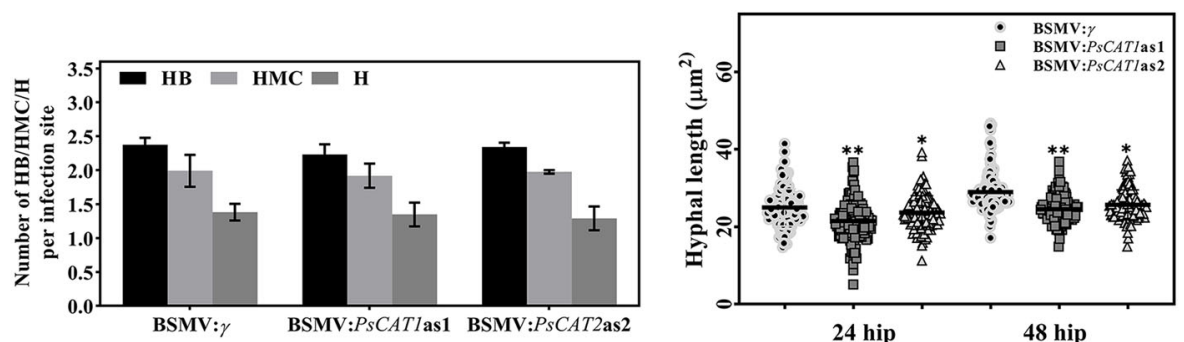

m

n
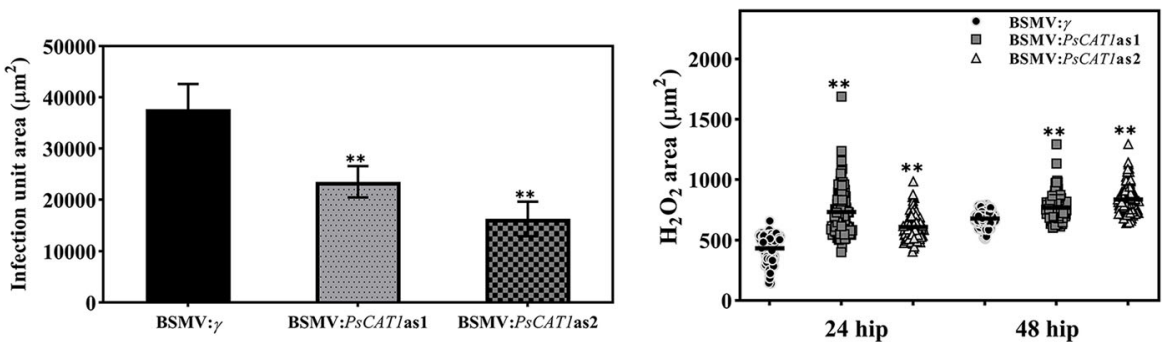

Fig. 7 Histological observation of fungal growth and host response in BSMV:Y and recombinant BSMV inoculated wheat leaves infected with CYR31. a-e. Fungal growth at 24 hpi (a) or 48 hpi (b), infection unit area at 120 hpi (c), $\mathrm{H}_{2} \mathrm{O}_{2}$ accumulation at 24 hpi (d) or 48 hpi (e) in BSMV:Y infected plants. f-j. Fungal growth at $24 \mathrm{hpi}(\mathbf{f})$ or $48 \mathrm{hpi}(\mathbf{g})$, infection unit area at $120 \mathrm{hpi}(\mathbf{h}), \mathrm{H}_{2} \mathrm{O}_{2}$ accumulation at $24 \mathrm{hpi}(\mathbf{i})$ or $48 \mathrm{hpi}(\mathbf{j})$ in BSMV:PSCAT1-infected plants, $\mathrm{H}_{2} \mathrm{O}_{2}$ accumulation was determined using DAB staining. $\mathbf{k}$. The average number of $\mathrm{HB}, \mathrm{HMC}$ and $\mathrm{H}$ showed no significant difference in HIGS plants infected by CYR31 compared with the control at 24 hpi. I. Hyphal length, which is the average distance from the junction of the substomatal vesicle and the hypha to the tip of the hypha, was clearly decreased in HIGS plants infected by CYR31 at 24 hpi. $\mathbf{m}$. The infection unit area at 120 hpi per infection unit was significantly reduced in HIGS plants infected by CYR31. $\mathbf{n}$. A significant increase in ROS accumulation was observed in CYR31-infected HIGS plants at 24 hpi. Values represent the means \pm SD of three independent samples. Differences were assessed using Student's $t$-test. Asterisks indicate $P<0.05$. SV, substomatal vesicle; HMC, haustorial mother cell; $1 H$, infection hypha; HB, hyphal branch; $\mathrm{H}$, haustoria

oryzae exhibits a moderate contribution to infection during the early stages (Tanabe et al., 2011). In this study, a BSMV-HIGS system was used to identify the role of PSCAT1 in the wheat-Pst interaction. The reduced disease symptoms in HIGS wheat seedlings infected by CYR31 suggested that the knockdown of PSCAT1 could reduce the virulence of Pst. In addition, $\mathrm{H}_{2} \mathrm{O}_{2}$ accumulation was obviously increased, and the fungal development was blocked. Previous studies have shown that ROS, especially $\mathrm{H}_{2} \mathrm{O}_{2}$, are highly toxic to pathogens
(Mittler, 2017). Therefore, we infer that accumulation of host-derived $\mathrm{H}_{2} \mathrm{O}_{2}$ in HIGS plants could impede fungal development during Pst infection, resulting in a decrease in the number of uredia. In addition, two extracellular SODs PsSOD1 and PsSOD2 have been identified as important virulence factors by catalyzing the conversion of superoxide anions to molecular oxygen and hydrogen peroxide (Liu et al., 2016; Zheng et al., 2020), while produced $\mathrm{H}_{2} \mathrm{O}_{2}$ is further detoxified by PsCAT1. Thus, based on the present results, an extracellular antioxidant 
enzyme system from Pst against host-derived ROS may be determined.

In summary, the present study revealed that PsCAT1, a heme-containing catalase, served as a virulence factor and potentially secreted during wheat-Pst interactions to contribute to Pst infection by scavenging host-derived ROS.

\section{Materials and methods}

\section{Experimental materials and growth conditions}

Wheat (Triticum aestivum L.) seedlings of the cultivar Suwon 11 (Su11) and N. benthamiana were grown in a greenhouse under $8 / 16 \mathrm{~h}$ night/day conditions at $16^{\circ} \mathrm{C}$ and $22^{\circ} \mathrm{C}$, respectively. Fresh urediniospores of the Pst pathotype CYR31 were collected from the infected wheat leaves for the wheat-Pst interaction study. To measure the expression levels of PsCAT1, PsCAT2 and PsCAT3 in the Pst-infected wheat leaves, the leaf tissues were sampled at $12 \mathrm{~h}, 24 \mathrm{~h}, 36 \mathrm{~h}$ and $48 \mathrm{~h}$ and stored at $-80^{\circ} \mathrm{C}$ for RNA extraction.

\section{Cloning and sequence analysis}

The sequences of all CATs from Pst were derived from the CYR32 genome (Zheng et al., 2013). Protein domains were analyzed using HMMER software (http:// www.ebi.ac.uk/Tools/hmmer/). Signal peptide prediction was performed using SignalP 4.1 Server software (http:// www.cbs.dtu.dk/services/SignalP/). The physicochemical properties of PsCAT1 were determined by the Compute $\mathrm{pI} / \mathrm{Mw}$ tool (http://web.expasy.org/compute_pi/). Mega 7.0 was used to construct a phylogenetic tree based on the neighbor-joining method. DNAMAN were used to determine nucleotide substitutions and the conservation of functional sites.

\section{RNA isolation and expression analysis}

Total RNA extraction and cDNA synthesis were performed as previously described (Liu et al., 2016). The expression levels of PsCAT1, PsCAT2 and PsCAT3 were measured during Pst infection of wheat by semiquantitative RT-PCR. Elongation factor-1 (EF-1) from Pst was used as an internal reference (Liu et al., 2016). Semi-quantitative RT-PCR was conducted using $40 \mathrm{cy}$ cles of $95^{\circ} \mathrm{C}$ for $30 \mathrm{~s}, 55^{\circ} \mathrm{C}$ for $30 \mathrm{~s}$ and $72^{\circ} \mathrm{C}$ for $5 \mathrm{~s}$. The primers used for semi-quantitative RT-PCR are listed in Supporting Information Table S1.

\section{Plasmid construction}

To biochemically characterize PsCAT1, the coding region sequences (CDS) of PSCAT1 without the signal peptide sequences was amplified and cloned into the EcoRI/XhoI restriction sites of vector pET15b-SUMO to obtain the recombinant plasmid pET15b-SUMOPSCAT1.
To determine polymerization of PsCAT1, the CDS of PsCAT1 without the signal peptide sequences was inserted into the EcoRI/BamHI sites of pGADT7 and pGBKT7 to generate the recombinant constructs pGADT7-PsCAT1 and pGBKT7-PsCAT1, respectively. In addition, PsCAT1 without the signal peptide sequences was also cloned into the $\mathrm{BamHI}$ restriction site in the binary vectors $\operatorname{PSPYNE}(\mathrm{R}) 173$ and $\operatorname{PSPYCE}(\mathrm{M})$ (Waadt et al., 2008) to generate the recombinant plasmids pSPYCE(M)-PsCAT1 and PSPYNE(R)173-PsCAT1, respectively.

To confirm the function of the identified signal peptide of PsCAT1, a yeast secretion system was established. The yeast signal trap vector pSUC2T7M13ORI (pSUC2), which carries a truncated invertase, SUC2, lacking both its initiation methionine and signal peptide, was used. DNA fragments encoding the predicted signal peptide of PsCAT1 was inserted into the EcoRI/XhoI restriction sites of vector pSUC2. The signal peptides of Avr1b (positive controls), and the sequence encoding the first 25 amino acids of Mg87 (negative control) were generated the recombinant plasmids pSUC2-Avr1 $b_{s p}$ and pSUC2-Mg87 ${ }_{1-75}$ (Gu et al., 2011).

To identify the function of PsCAT1, the CDS of PSCAT1 sequences was amplified and inserted into the NotI/BamHI restriction sites in plasmid pDR195 to obtain the complementation construct pDR195-PSCAT1.

For transient expression of PSCAT1 in tobacco, the CDS of PSCAT1 without a signal peptide and the Bax gene were PCR-amplified and inserted into the ClaI/ Not I restriction sites in vector potato virus X (PVX) to obtain the recombinant plasmids PVX-PSCAT1 and PVX-Bax, respectively.

Construction of the recombinant BSMV-HIGS vectors was performed as described by Holzberg et al. (2002). To specifically silence the PsCAT1 gene, the two $\gamma$ RNA-based derivative plasmids BSMV-PsCAT1as1 and BSMV-PSCAT1as2 were constructed using a 142-bp fragment and a 133-bp fragment, which exhibited the highest polymorphism in the CAT gene family of Pst and the lowest nucleotide sequence similarity with other genes from Pst and wheat.

The primers used for all constructs are listed in Table S1.

\section{Expression and enzymatic characterization of PsCAT1}

The PsCAT1 gene was amplified by PCR using a Pst-infected wheat cDNA sample as a template. The constructed recombinant plasmid $\mathrm{pET} 15 \mathrm{~b}$-sumo-PSCAT1 was transformed into E. coli BL21(DE3) plysS and then protein expression was induced by $0.4 \mathrm{mM}$ IPTG supplement overnight at $16^{\circ} \mathrm{C}$. The collected cells were suspended in ice-cold phosphate-buffered saline (PBS) solution and lysed by sonication. 
The supernatant containing the soluble proteins was analyzed by SDS-PAGE, and protein purification was performed using a HisTrap FF affinity column (GE Healthcare, Uppsala, Sweden), and identified by Western blotting analysis as described by Liu et al. (2016).

CAT activity was assayed using Catalase Assay Kit (Beyotime Biotechnology, China, Beijing) according to the manufacturer's instructions. The optimum temperature and $\mathrm{pH}$ of the purified enzyme were determined after the enzyme solution samples were incubated at 20 to $70^{\circ} \mathrm{C}$ and $\mathrm{pH} 3$ to 13 for $30 \mathrm{~min}$, respectively. The effects of four metal ions $\left(0.1 \mathrm{mM} \mathrm{Mn}{ }^{2+}, \mathrm{Zn}^{2+}\right.$, $\mathrm{Cu}^{2+}$, or $\mathrm{Fe}^{2+}$ ) on the CAT activity were measured. In addition, the dynamic curve was constructed to determine $K \mathrm{~m}$ and $V \max$ values. All assays were repeated three times.

\section{Size-exclusion chromatography analysis of PsCAT1}

The PSCAT1 protein sample was purified by nickel ion affinity chromatography, dialysis to remove salt, and cation exchange chromatography. The native molecular weight of PsCAT1 was then determined using size exclusion chromatography. The samples were loaded into a Superdex ${ }^{\mathrm{Tm}} 200$ column (GE Healthcare) equilibrated in $50 \mathrm{mM}$ PBS, pH 7.4, at a flow rate of $0.5 \mathrm{ml} \mathrm{min}^{-1}$ for preparative-scale fractionation. Protein fractions were collected based on UV absorbance at $280 \mathrm{~nm}$ and the elution times. The column was calibrated by chromatographic protein standards (thyroglobulin, $669 \mathrm{kDa}$; globulin, $158 \mathrm{kDa}$; ovalbumin, $44 \mathrm{kDa}$; carbonic anhydrase, $29 \mathrm{kDa}$; ribonuclease A $13.7 \mathrm{kDa}$ ).

\section{Yeast two-hybrid assays}

Self-interactions of PsCAT1 were investigated by cotransformation of the recombinant plasmids pGBKT7PSCAT1 and pGADT7-PsCAT1 into the yeast strain AH109. Transformed cells were cultured on SD (synthetic dropout)-Leu-Trp (SD-LW) and SD-Leu-Trp-His (SD-LWH) media at $30{ }^{\circ} \mathrm{C}$ for 3 days. A single colony was cultured and serial 1:10 dilutions were plated in either SD-Leu-Trp-His-Ade (SD-LWHA) or SD-LWHA containing $\mathrm{X}-\alpha-\mathrm{Gal}$ media. Cell growth was observed 3 days after plating.

Co-transformations with pGBKT7-Lam and pGADT7T, pGADT7 and pGBKT7-PsCAT1, and pGBKT7 and pGADT7-PSCAT1 were used as the negative controls, whereas Co-transformation with pGBKT7-53 and pGADT7-T was used as the positive control.

\section{BiFC assay in $N$. benthamiana}

The recombinant plasmids pSPYNE(R)173-PSCAT1 or pSPYCE(M)-PsCAT1 were individually transformed into A. tumefaciens strain GV3101 and co-infiltrated into $N$. benthamiana leaves. After $48 \mathrm{~h}$, self-interaction of
PsCAT1 was determined by monitoring yellow fluorescent protein (YFP) signal by confocal microscopy, with an excitation laser at $488 \mathrm{~nm}$. Yn:TaSGT1 and TaRAR1: Yc were used as the positive control (Wang et al., 2015). All of the assays were repeated independently at least three times with comparable results.

\section{Functional validation of the signal peptide}

To confirm the function of the predicted signal peptide of PsCAT1, the yeast signal sequence trap system was used as described previously (Yin et al., 2018). The recombinant vector pSUC2-PSCAT1 $1_{S P}$ was transformed into the invertase mutant yeast strain YTK12 (Oh et al., 2009). In this experiment, the signal peptides of Avr1b form Phytophthora sojae was used as positive controls, and the first 25 amino acids of a non-secreted protein from $M$. oryzae Mg87 was used as a negative control (Gu et al., 2011). CMD-W medium ( $0.67 \%$ yeast nitrogen base (YNB) without amino acids, $0.075 \%$ tryptophan dropout supplement, $2 \%$ sucrose, $0.1 \%$ glucose and $2 \%$ agar) and YPRAA medium (1\% yeast extract, $2 \%$ peptone, $2 \%$ raffinose, $2 \mathrm{mg} \mathrm{ml}^{-1}$ antimycin $\mathrm{A}$ and $2 \%$ agar) were prepared to determine the secretory function of the signal peptide. Moreover, invertase enzymatic activity was detected by the reduction of TTC to insoluble red colored TPF according to procedures and conditions described previously (Zheng et al., 2020).

\section{Heterologous expression of PSCAT1 in S. cerevisiae}

To identify the function of PsCAT1, the recombinant plasmids pDR195-PSCAT1 and pDR195 were transformed into a S. cerevisiae strain YNL24C, respectively. The positive transformants carrying the pDR195PSCAT1 vector were confirmed by PCR analysis. Then, the function of PSCAT1 was determined based on the growth of the positive transformants in SC media with different concentrations of $\mathrm{H}_{2} \mathrm{O}_{2}$. Growth was monitored in $\mathrm{SC}$ with different carbon sources as previously described by Longo et al. (1996). Yeast cells grown in SC without uracil were standardized to $1 \times 10^{7} \mathrm{cells} / \mathrm{ml}$. Five microliter volumes of a 10 -fold dilution series were then spotted on the surface of SC agar plates. The plates were incubated and cell growth was observed for $48 \mathrm{~h}$ at $30{ }^{\circ} \mathrm{C}$. The $S$. cerevisiae strain containing the empty pDR195 vector was used as the control.

\section{A. tumefaciens mediated transient expression of PsCAT1}

The A. tumefaciens-mediated transient expression method was used to assay suppression of Bax-induced cell death by PsCAT1. The recombinant plasmids PVXHA-PsCAT1, PVX-HA-GFP and PVX-Bax were transformed into A. tumefaciens strain GV3101, respectively. The confirmed positive $A$. tumefaciens cells carrying PVX-HA-PsCAT1 and PVX-HA-GFP at a final OD600 
of 0.4 and $10 \mathrm{mM} \mathrm{MgCl} 2$ buffer were infiltrated into $N$. benthamiana leaves. After $24 \mathrm{~h}$, the same infiltration site was challenged with $A$. tumefaciens cell suspensions carrying the Bax gene. The infected leaves were harvested to extract total proteins for Western blotting analysis at 72 hpi. After 6 to 8 dpi, symptoms of the leaves were monitored and recorded.

In addition, the infected leaves were stained by trypan blue and $\mathrm{DAB}$ respectively. The leaves were then photographed after decolorized and transparentized.

\section{BSMV-mediated PsCAT1 silencing in the compatible wheat-Pst interaction}

For silencing of PSCAT1, construction of the recombinant vectors ( $\gamma$-PsCAT1-as1 and $\gamma$-PsCAT1-as2) viral inoculation were performed as described previously by Holzberg et al. (2002). The wheat plants inoculated with BSMV-TaPDS (phytoene desaturase) were used as the positive control, whereas the BSMV- $\gamma$-inoculated plants were acted as the negative control. The wheat seedlings after inoculation were incubated in a plant growth chamber for $9-10$ days at $25-27^{\circ} \mathrm{C}$. Then, the fourth leaves were further infected with fresh CYR31 urediospores (for silencing of PSCAT1), and sampled at 0,12, 24, 48, 72 and 120 hpi for silencing efficiency calculations and histological observation (Wang et al., 2007). Fungal biomass was measured as previously described (Liu et al., 2016). The infected leaves were assessed for phenotype identification and photographed at $15 \mathrm{dpi}$. Biological replicates were carried out in triplicate.

\section{Histological observation of fungal growth and host response}

To characterize the function of PSCAT1 in the wheat-Pst infections, the fungal development and host response were observed by microscopy. The leaf segments were fixed and stained as described in Wang et al. (2007). $\mathrm{H}_{2} \mathrm{O}_{2}$ accumulation was detected by staining with DAB (Amresco, Solon, OH, USA). The Pst infection structures were stained with wheat germ agglutinin (WGA) conjugated to Alexa Fluor-488 (Invitrogen, Carlsbad, CA, USA) and observed under blue-light excitation (excitation wavelength $450-480 \mathrm{~nm}$, emission wavelength $515 \mathrm{~nm}$ ) with a BX51 Microscope (Olympus). Haustorial mother cells, haustoria, hyphal length and branches as well as colony size were analyzed statistically as previously described (Liu et al., 2016). Only the infection site where an appressorium had formed over a stoma was considered to be a successful penetration. A minimum of 50 infection sites from five randomly selected leaf segments were detected for each treatment.

\section{Abbreviations}

ROS: Reactive oxygen species; CAT: Catalase; SOD: Superoxide dismutase: HIGS: Host-induced gene silencing; APX: Ascorbate peroxidase;
GPX: Glutathione peroxidase; PRX: Peroxiredoxin; GSH: Glutathione; sqRTPCR: Semi-quantitative reverse transcription-PCR; qRT-PCR: Quantitative reverse transcription-PCR; ORF: Open reading frame; BiFC: Bimolecular fluorescence complementation; EF-1: Elongation factor-1; CDS: Coding region sequences; PBS: Phosphate-buffered saline; YNB: Yeast nitrogen base; TTC: 2,3,5-Triphenyltetrazolium chloride; TPF: 1,3,5-Triphenylformazan; SC: Synthetic complete; BSMV: Barley stripe mosaic virus; WGA: Wheat germ agglutinin; HB: Hyphal branches; HMC: Haustorial mother cells; H: Haustoria; PDS: Phytoene desaturase; PVX: potato virus $X$

\section{Supplementary Information}

The online version contains supplementary material available at https://doi. org/10.1007/s44154-021-00021-2.

Additional file 1: Fig. S1. Prediction of the signal peptide of PSCATs. (a) PsCAT1 (b) PSCAT2 (c) PsCAT3 (d) PsCAT4 were predicted using SignalP 4.1 (http://www.cbs.dtu.dk/services/SignalP/). Fig. S2. Transcription profile analysis of PSCATs during the early stage of Pst infection. The transcript levels of PSCAT1, PSCAT2, PSCAT3 at non-germinated urediniospores, 12, 24, 36, 48 hip, were analyzed by semi-quantitative RT-PCR (sqRT-PCR) with PstEF1 as control. U, urediniospore. Fig. S3. Prediction of conserved domains of PsCAT1. (a) The protein domains and (b) The metal binding and active sites of catalytic reaction of PSCAT1 were predicted by Pfam (http://pfam.sanger.ac.uk/) and Uniport (https://www.uniprot.org/), respectively. Fig. S4. Phylogenetic analysis of PSCAT1 and selected homologous proteins from other fungi. The unrooted phylogram was constructed based on the NJ method. The confidence level for the groupings was estimated using 1000 bootstrap replicates. The numbers adjacent to the branch points indicate the percentage of replicates supporting each branch. Fig. S5. Determination of the molecular weight of PsCAT1 by chromatography. (a) Gel filtration verifies the site where UV absorption peaks of protein sample. (b) Western blotting analysis of the sample at the absorption peak. Lane 1 is before chromatography, lane 2 is after chromatography. (c) Verification of the existence form of PSCAT1 after depolymerization. (d) Western blotting analysis of sample at the absorption peak. The arrow indicates the protein PSCAT1. M, maker. Fig. S6. Transient expression of PSCAT1 in N. benthamiana. (a) Five injection sites on tobacco leaves. 1, PsCAT1; 2, PsCAT1 + Bax (infiltration 24 h later); 3, empty vector; 4, empty vector + Bax (infiltration 24 h later); 5, Bax. (b) Western blotting analysis of protein expression in $\mathrm{N}$. benthamiana through GFP, HA and Bax antibodies. Ponceau S staining of the membrane indicates equal loading of proteins. Fig. S7. HIGS of PSCAT1 led to restricted fungal development. (a) The average number of $\mathrm{HB}, \mathrm{HMC}$ and $\mathrm{H}$ showed no significant difference in HIGS plants infected by CYR31 compared with the control at 48 hpi. (b) The infection unit area at 24 and 48 hpi per infection unit in HIGS plants infected by CYR31 was similar to that of the control. Values represent the means \pm standard errors of three independent samples. Differences were assessed using Student's t-

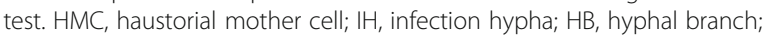
$\mathrm{H}$, haustoria. Table S1. Oligonucleotides and strains used in this study.

\section{Acknowledgements}

This research was supported by the National Natural Science Foundation of China (31620103913 and U2003118), Natural Science Basic Research Plan in Shaanxi Province of China (2020JZ-12), National "111 plan" (BP0719026) and Shaanxi Innovation Team Project (2018TD-004).

\section{Code availability \\ Not applicable.}

\section{Authors' contributions}

P.Y., W.-H.Q., Z.-S.K. and J.L. designed the experiments; P.Y. and W.-H.Q. analyzed the data; P.Y., W.-H.Q., L.-H.J., C.-H.J. and X.-X.M. performed experiments; P.Y. drafted the article; Z.-S.K. and J.L. revised and finalized the manuscript. The authors read and approved the final manuscript.

\section{Funding}

This research was supported by the National Natural Science Foundation of China (31620103913 and U2003118), Natural Science Basic Research Plan in 
Shaanxi Province of China (2020JZ-12), National "111 plan" (BP0719026) and Shaanxi Innovation Team Project (2018TD-004).

\section{Availability of data and materials}

All data generated or analyzed during this study are included in this published article and its supplementary information files.

\section{Declarations}

Ethics approval and consent to participate

Not applicable.

\section{Consent for publication}

Not applicable.

\section{Competing interests}

The authors declare no conflict of interest. Z.-S.K. is a member of the editorial board but was not involved in the journal's review or any decisions related to this submission.

Received: 20 August 2021 Accepted: 22 November 2021

Published online: 29 December 2021

\section{References}

Benoit SL, Maier RJ (2016) Helicobacter catalase devoid of catalytic activity protects the bacterium against oxidative stress. J Biol Chem 291(45):2336623373. https://doi.org/10.1074/jbc.M1 16.747881

Calera JA, Paris S, Monod M, Hamilton AJ, Debeaupuis JP, Diaquin M, LópezMedrano R, Leal F, Latgé JP (1997) Cloning and disruption of the antigenic catalase gene of Aspergillus fumigatus. Infect Immun 65(11):4718-4724. https://doi.org/10.1128/iai.65.11.4718-4724.1997

Chang Q, Liu J, Lin XH, Hu SJ, Yang Y, Li D, Chen LY, Huai BY, Huang LL, Voegele RT, Kang ZS (2017) A unique invertase is important for sugar absorption of an obligate biotrophic pathogen during infection. New Phytol 215(4):15481561. https://doi.org/10.1111/nph.14666

Chelikani P, Fita I, Loewen PC (2004) Diversity of structures and properties among catalases. Cell Mol Life Sci 61(2):192-208. https://doi.org/10.1007/s00018003-3206-5

Cuéllar-Cruz M, Briones-Martin-del-Campo M, Cañas-Villamar I, MontalvoArredondo J, Riego-Ruiz L, Castaño I, De Las PA (2008) High resistance to oxidative stress in the fungal pathogen Candida glabrata is mediated by a single catalase, Cta1 $p$, and is controlled by the transcription factors Yap1p, Skn7p, Msn2p, and Msn4p. Eukaryot Cell 7(5):814-825. https://doi.org/10.112 8/EC.00011-08

Dong W, Hou Y, Li S, Wang F, Zhou J, Li Z, Wang Y, Huang F, Fu L, Huang Y, Cui $Z$ (2015) Purification, cloning, expression, and biochemical characterization of a monofunctional catalase, KatP, from Pigmentiphaga sp. DL-8. Protein Expr Purif 108:54-61. https://doi.org/10.1016/.jpep.2015.01.011

Foyer $\mathrm{CH}$, Noctor $\mathrm{G}$ (2005) Redox homeostasis and antioxidant signaling: a metabolic interface between stress perception and physiological responses. Plant Cell 17(7):1866-1875. https://doi.org/10.1105/tpc.105.033589

Garre V, Müller U, Tudzynski P (1998) Cloning, characterization and targeted disruption of cpcat1, coding for an in planta secreted catalase of Claviceps purpurea. Mol Plant-Microbe Interact 11(8):772-783. https://doi.org/10.1094/ MPMI.1998.11.8.772

González J, Castillo R, García-Campos MA, Noriega-Samaniego D, EscobarSánchez V, Romero-Aguilar L, Alba-Lois L, Segal-Kischinevzky C (2020) Tolerance to oxidative stress in budding yeast by heterologous expression of catalases a and T from Debaryomyces hansenii. Curr Microbiol 77(12):40004015. https://doi.org/10.1007/s00284-020-02237-3

Gu B, Kale SD, Wang QH, Wang DH, Pan QN, Cao H, Cao H, Meng YL, Kang ZS, Tyler BM, Shan WX (2011) Rust secreted protein Ps87 is conserved in diverse fungal pathogens and contains a RXLR like motif sufficient for translocation into plant cells. PLoS One 6(11):e27217. https://doi.org/10.1371/journal.pone.0027217

Guo Y, Yao S, Yuan T, Wang YZ, Zhang D, Tang WH (2019) The spatiotemporal control of KatG2 catalase-peroxidase contributes to the invasiveness of fusarium graminearum in host plants. Mol Plant Pathol 20(5):685-700. https:// doi.org/10.1111/mpp.12785

Holzberg S, Brosio P, Gross C, Pogue GP (2002) Barley stripe mosaic virus-induced gene silencing in a monocot plant. Plant J 30(3):315-327. https://doi.org/10.1 046/j.1365-313x.2002.01291.x
Jamieson DJ (1998) Oxidative stress responses of the yeast Saccharomyces cerevisiae. Yeast 14(16):1511-1527. https://doi.org/10.1002/(SICI)1097-0061 (199812)14:16<1511::AID-YEA356>3.0.CO;2-S

Kapetanaki SM, Zhao X, Yu S, Magliozzo RS, Schelvis JP (2007) Modification of the active site of mycobacterium tuberculosis KatG after disruption of the met-TyrTrp cross-linked adduct. J Inorg Biochem 101(3):422-433. https://doi.org/10.1 016/j.jinorgbio.2006.11.004

Kawasaki L, Wysong D, Diamond R, Aguirre J (1997) Two divergent catalase genes are differentially regulated during aspergillus nidulans development and oxidative stress. J Bacteriol 179(10):3284-3292. https://doi.org/10.1128/ jb.179.10.3284-3292.1997

Lee DH, Oh DC, Oh YS, Malinverni JC, Kukor JJ, Kahng HY (2007) Cloning and characterization of monofunctional catalase from photosynthetic bacterium Rhodospirillum rubrum S1. J Microbiol Biotechnol 17(9):1460-14688

Liu J, Guan T, Zheng PJ, Chen LY, Yang Y, Huai BY, Li D, Chang Q, Huang LL, Kang ZS (2016) An extracellular Zn-only superoxide dismutase from Puccinia striiformis confers enhanced resistance to host-derived oxidative stress. Environ Microbiol 18(11):4118-4135. https://doi.org/10.1111/1462-2920.13451

Mittler R (2017) ROS are good. Trends Plant Sci 22(1):11-19. https://doi.org/10.101 6/j.tplants.2016.08.002

Mittler R, Vanderauwera S, Gollery M, Van BF (2004) Reactive oxygen gene network of plants. Trends Plant Sci 9(10):490-498. https://doi.org/10.1016/j. tplants.2004.08.009

Montibus M, Pinson-Gadais L, Richard-Forget F, Barreau C, Ponts N (2015) Coupling of transcriptional response to oxidative stress and secondary metabolism regulation in filamentous fungi. Crit Rev Microbiol 41(3):295-308. https://doi.org/10.3109/1040841X.2013.829416

Morales Hernandez CE, Padilla Guerrero IE, Gonzalez Hernandez GA, Salazar Solis E, Torres Guzman JC (2010) Catalase overexpression reduces the germination time and increases the pathogenicity of the fungus Metarhizium ansiopliae. Appl Microbiol Biotechnol 87(3):1033-1044. https://doi.org/10.1007/s00253-010-2517-3

Nathues E, Joshi S, Tenberge KB, von den Driesch M, Oeser B, Bäumer N, Mihlan M, Tudzynski P (2004) CPTF1, a CREB-like transcription factor, is involved in the oxidative stress response in the phytopathogen Claviceps purpurea and modulates ROS level in its host Secale cereale. Mol Plant-Microbe Interact 17(4):383-393. https://doi.org/10.1094/MPMI.2004.17.4.383

Navarro RE, Stringer MA, Hansberg W, Timberlake WE, Aguirre J (1996) CatA, a new Aspergillus nidulans gene encoding a developmentally regulated catalase. Curr Genet 29(4):352-359

Nicholls P, Fita I, Loewen PC (2001) Enzymology and structure of catalases. Adv Inorg Chem 51:51-106. https://doi.org/10.1016/S0898-8838(00)51001-0

Oh SK, Young C, Lee M, Oliva R, Bozkurt TO, Cano LM, Win J, Bos Jl, Liu HY, van Damme M, Morgan W, Choi D, Van der Vossen EA, Vleeshouwers VG, Kamoun S (2009) In planta expression screens of Phytophthora infestans RXLR effectors reveal diverse phenotypes, including activation of the solanum bulbocastanum disease resistance protein Rpi-blb2. Plant Cell 21(9):29282947. https://doi.org/10.1105/tpc.109.068247

Scherer M, Wei H, Liese R, Fischer R (2002) Aspergillus nidulans catalaseperoxidase gene (cpeA) is transcriptionally induced during sexual development through the transcription factor StuA. Eukaryot Cell 1(5):725735. https://doi.org/10.1128/EC.1.5.725-735.2002

Skamnioti P, Henderson C, Zhang Z, Robinson Z, Gurr SJ (2007) A novel role for catalase $B$ in the maintenance of fungal cell-wall integrity during host invasion in the rice blast fungus Magnaporthe grisea. Mol Plant-Microbe Interact 20(5):568-580. https://doi.org/10.1094/MPMI-20-5-0568

Sooch BS, Kauldhar BS, Puri M (2014) Recent insights into microbial catalases: isolation, production and purification. Biotechnol Adv 32(8):1429-1447. https://doi.org/10.1016/j.biotechadv.2014.09.003

Tanabe S, Ishii-Minami N, Saitoh K, Otake Y, Kaku H, Shibuya N, Nishizawa Y, Minami E (2011) The role of catalase-peroxidase secreted by Magnaporthe oryzae during early infection of rice cells. Mol Plant-Microbe Interact 24(2): 163-171. https://doi.org/10.1094/MPMI-07-10-0175

Vetrano AM, Heck DE, Mariano TM, Mishin V, Laskin DL, Laskin JD (2005) Characterization of the oxidase activity in mammalian catalase. J Biol Chem 280(42):35372-35381. https://doi.org/10.1074/jbc.M503991200

Waadt R, Schmidt LK, Lohse M, Hashimoto K, Bock R, Kudla J (2008) Multicolor bimolecular fluorescence complementation reveals simultaneous formation of alternative CBL/CIPK complexes in planta. Plant J 56(3):505-516. https:// doi.org/10.1111/j.1365-313X.2008.03612.x

Wang CF, Huang LL, Buchenauer H, Han QM, Zhang HC, Kang ZS (2007) Histochemical studies on the accumulation of reactive oxygen species $\left(\mathrm{O}_{2}^{-}\right.$ 
and $\mathrm{H}_{2} \mathrm{O}_{2}$ ) in the incompatible and compatible interaction of wheat-Puccinia striiformis f. sp. tritici. Physiol Mol Plant Pathol 71(4-6):230-239. https://doi. org/10.1016/j.pmpp.2008.02.006

Wang GF, Fan R, Wang X, Wang D, Zhang X (2015) TaRAR1 and TaSGT1 associate with TaHsp90 to function in bread wheat (Triticum aestivum L.) seedling growth and stripe rust resistance. Plant Mol Biol 87(6):577-589. https://doi. org/10.1007/s11103-015-0298-x

Wang ZL, Zhang LB, Ying SH, Feng MG (2013) Catalases play differentiated roles in the adaptation of a fungal entomopathogen to environmental stresses. Environ Microbiol 15(2):409-418. https://doi.org/10.1111/j.1462-2920.2012.02 848.x

Wysong DR, Christin L, Sugar AM, Robbins PW, Diamond RD (1998) Cloning and sequencing of a Candida albicans catalase gene and effects of disruption of this gene. Infect Immun 66(5):1953-1961. https://doi.org/10.1128/IAl.66.5.1 953-1961.1998

Yamashita K, Shiozawa A, Banno S, Fukumori F, Ichiishi A, Kimura M, Fujimura M (2007) Involvement of OS-2 MAP kinase in regulation of the large-subunit catalases CAT-1 and CAT-3 in Neurospora crassa. Genes Genet Syst 82(4):301310. https://doi.org/10.1266/ggs.82.301

Yang H, Zhang X, Ma Z, Xu N, Liu J (2020) Expression, purification and characterization of catalase from Conynebacterium glutamicum. Chin J Biotechnol 36(8):1568-1577. https://doi.org/10.13345/j.cjb.190544

Yu C, Wang N, Wu M, Tian F, Chen H, Yang F, Yuan X, Yang CH, He C (2016) OxyR-regulated catalase CatB promotes the virulence in rice via detoxifying hydrogen peroxide in Xanthomonas oryzae pv. Oryzae. BMC Microbiol 16(1): 269. https://doi.org/10.1186/s12866-016-0887-0

Yuan F, Yin S, Xu Y, Xiang L, Wang H, Li Z, Li Z, Fan K, Pan G (2021) The richness and diversity of catalases in Bacteria. Front Microbiol 12:645477. https://doi. org/10.3389/fmicb.2021.645477

Zámocký M, Koller F (1999) Understanding the structure and function of catalases: clues from molecular evolution and in vitro mutagenesis. Prog Biophys Mol Biol 72(1):19-66. https://doi.org/10.1016/s0079-6107(98)00058-3

Zhang Z, Henderson C, Gurr SJ (2004) Blumeria graminis secretes an extracellular catalase during infection of barley: potential role in suppression of host defence. Mol Plant Pathol 5(6):537-547. https://doi.org/10.1111/j.1364-3703.2 004.00251.x

Zheng P, Chen L, Zhong SX, Wei XB, Zhao Q, Pan QL, Kang ZS, Liu J (2020) A cuonly superoxide dismutase from stripe rust fungi functions as a virulence factor deployed for counter defense against host-derived oxidative stress. Environ Microbiol 22(12):5309-5326. https://doi.org/10.1111/1462-2920.15236

Zheng WM, Huang LL, Huang JQ, Wang XJ, Chen XM, Zhao J, Guo J, Zhuang H, Qiu C, Liu J, Liu H, Huang X, Pei G, Zhan G, Tang C, Cheng Y, Liu M, Zhang J, Zhao Z, Zhang S, Han Q, Han D, Zhang H, Zhao J, Gao X, Wang J, Ni P, Dong W, Yang L, Yang H, Xu JR, Zhang G, Kang Z (2013) High genome heterozygosity and endemic genetic recombination in the wheat stripe rust fungus. Nat Commun 4(1):2673. https://doi.org/10.1038/ncomms3673

Zhu Z, Yang M, Bai Y, Ge F, Wang S (2020) Antioxidant-related catalase CTA1 regulates development, aflatoxin biosynthesis, and virulence in pathogenic fungus aspergillus flavus. Environ Microbiol 22(7):2792-2810. https://doi.org/1 $0.1111 / 1462-2920.15011$

Michán S, Lledías F, Baldwin JD, Natvig DO, Hansberg W (2002) Regulation and oxidation of two large monofunctional catalases. Free Radic Biol Med 33(4): 521-32. https://doi.org/10.1016/s0891-5849(02)00909-7

Paris S, Wysong D, Debeaupuis JP, Shibuya K, Philippe B, Diamond RD, Latgé JP (2003) Catalases of Aspergillus fumigatus. Infect Immun 71(6):3551-62. https:// doi.org/10.1128/AAl.71.6.3551-3562.2003

Huai B, Yang Q, Qian YR, Qian WH, Kang ZS, Li J (2019) ABA-Induced Sugar Transporter TaSTP6 Promotes Wheat Susceptibility to Stripe Rust. Plant Physiol 181(3):1328-43. https://doi.org/10.1104/pp.19.00632

Yin W, Wang, Y, Chen T, Lin Y, Luo C (2018) Functional Evaluation of the Signal Peptides of Secreted Proteins. Bio Protoc 8(9):e2839. https://doi.org/10.21769/ BioProtoc.2839

Longo VD, Gralla EB, Valentine JS (1996) Superoxide dismutase activity is essential for stationary phase survival in Saccharomyces cerevisiae: Mitochondrial production of toxic oxygen species in vivo. J Biol Chem 271(21):12275-12280 https://doi.org/10.1074/jbc.271.21.12275

\section{Publisher's Note}

Springer Nature remains neutral with regard to jurisdictional claims in published maps and institutional affiliations. 